\title{
ANÁLISE E CARACTERIZAÇÃO DE SOLO EM PROPRIEDADE RURAL SITUADA NO TERRITÓRIO DE IDENTIDADE DO MÉDIO SUDOESTE DA BAHIA
}

Pedro Augusto Ferraz e Silva - pedroaugsto@ outlook.com

Universidade Estadual do Sudoeste da Bahia

Breno Lopes Souza - breno_lopes.s@ hotmail.com

Universidade Estadual do Sudoeste da Bahia

Dimitre Souza de Moura - dimitredm@gmail.com

Universidade Estadual do Sudoeste da Bahia

Waldech Junior - waldech.junior9@gmail.com

Universidade Estadual do Sudoeste da Bahia

Lidia Raiza Sousa Lima Chaves Trindade - lidiaraiza@hotmail.com

Universidade Estadual do Sudoeste da Bahia 


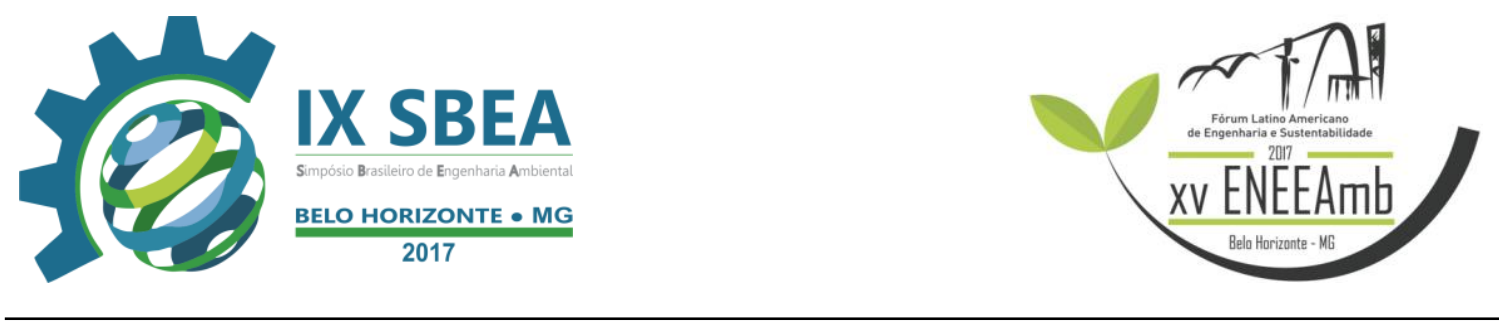

\section{RESUMO}

Este trabalho foi realizado na região do território de identidade do médio sudoeste da Bahia, cujo principal atividade econômica é a pecuária. Dentre os principais problemas relacionados com a pecuária brasileira estão, a degradação dos solos, o manejo animal inadequado, a baixa reposição de nutrientes no solo, os impedimentos físicos dos solos e os baixos investimentos tecnológicos.

O conhecimento destas propriedades do solo, favorece a otimização para o uso de insumos nas áreas destinadas ao cultivo e é capaz de fornecer um parecer de quais atividades poderão ser desenvolvidas em determinada área com intuito de obter maior produtividade.

Este estudo foi feito para avaliar qualitativamente o solo em uma propriedade rural com a atividade predominante da pecuária, afim de constatar as necessidades do solo, para posteriormente recuperar ás áreas degradadas pela pecuária extensiva com a implantação de um sistema agroflorestal. Os resultados das análises de matéria orgânica refletem as consequências do histórico de utilização de solo na região do sudoeste baiano, cujo principal atividade econômica é a pecuária extensiva. Embora o solo tenha sido caracterizado como compactado, devido à dificuldade de coleta, os resultados das análises de capacidade de campo mostraram uma boa capacidade de infiltração durante os ensaios laboratoriais.

Permitiu concluir que a microrregião estudada possui boas condições para as plantas nativas do local. Com relação à baixa concentração de matéria orgânica, será realizada a transposição de serapilheira de remanescentes da vegetação nativa, pois esta tem como função principal, proteção e adubação gradual do solo. Serão realizadas análises periódicas para acompanhar as mudanças nas características do solo em consequência da instalação e manejo dos módulos agroflorestais.

\section{INTRODUÇÃO/OBJETIVO}

As práticas agropecuárias convencionais têm causado degradação das propriedades do solo, principalmente de sua estrutura, favorecendo a erosão hídrica e o assoreamento de rios, córregos e lagos. (ARGENTON, 2000).

Em relação a atividade pecuária, uma das principais causas da degradação em áreas destinadas a criação de bovinos é a compactação do solo, causada principalmente pelo pisoteio animal nas áreas de pastagem. A compactação do solo reduz a aeração e a infiltração de água e aumenta a resistência do solo em relação a penetração das raízes. (ALBUQUERQUE et al., 2001) 


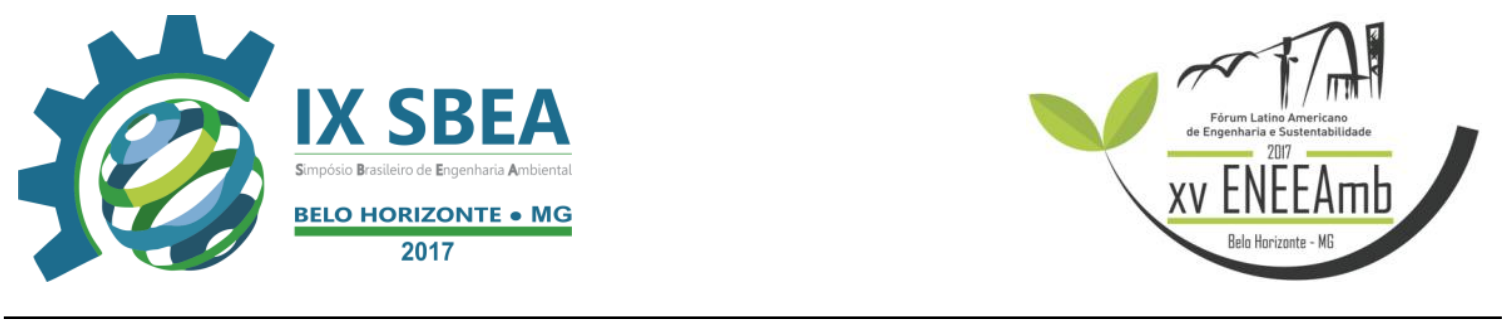

Aidar \& Kluthcouski (2003) alertam que, entre os principais problemas da pecuária brasileira estão, a degradação dos solos, o manejo animal inadequado, a baixa reposição de nutrientes no solo, os impedimentos físicos dos solos e os baixos investimentos tecnológicos.

A falta de conhecimento das características e propriedades do solo, aliada ao manejo pecuário extensivo, têm levado à aceleração da erosão física e biológica dos solos bem como a processos mais agressivos, como é o caso da desertificação. (BALSAN, 2006)

Com isso, as propriedades físicas e químicas do solo merecem grande importância, pois influenciam a produtividade, através do desenvolvimento das plantas. Muitas dessas propriedades têm sido utilizadas para quantificar as alterações provocadas pelos diferentes sistemas de manejo ou até mesmo como indicadores da sua qualidade (NEVES et al., 2007).

A utilização de sistemas agroflorestais tem sido, nas últimas décadas, bastante difundida como alternativa para recuperação de áreas degradadas, atribuindo-se à combinação de espécies arbóreas com culturas agrícolas e, ou, animais a melhoria nas propriedades físico-químicas de solos degradados, bem como na atividade de microrganismos, considerando a possibilidade de um grande número de fontes de matéria orgânica (Reinert, 1998; Mendonça et al., 2001).

O conhecimento destas propriedades do solo, favorece a otimização para o uso de insumos nas áreas destinadas ao cultivo ou criação de animais, bem como é capaz fornecer um parecer de quais atividades poderão ser desenvolvidas em determinada área com intuito de obter maior produtividade. (BORGHI \& CRUSCIOL, 2007)

$\mathrm{O}$ presente trabalho teve como objetivo analisar o $\mathrm{pH}$, umidade total e ao ar, capacidade de campo e matéria orgânica, de uma amostra de solo coletada em uma propriedade rural situada no território de identidade do médio sudoeste da Bahia, afim de constatar as necessidades do solo para posteriormente recuperar ás áreas degradadas pela pecuária extensiva com a implantação de um sistema de agroflorestal.

\section{METODOLOGIA}


- 1 Galinhota; 1 Enxada; 1 Cavadeira tipo light; 1 Pá de ferro; 1 Caixa térmica MOR de 341; 2 Sacolas plásticas de polietileno de alta densidade; 1 Pipeta graduada; 4 Becker; 3 Buretas; 4 Erlenmeyer; 1 Estufa de esterilização e secagem; 4 Recipientes de alumínio; 1 Conta gotas; Ácido Sulfúrico; Ácido fosfórico; Cloreto de cálcio; Sulfato ferroso; Cloreto de prata; Indicador difenilamina.

\section{Local onde foi realizada a coleta da amostra de solo:}

A amostra de solo foi coletada em uma propriedade rural situada no território de identidade do médio sudoeste da Bahia.

\section{Território de Identidade do Médio Sudoeste da Bahia}

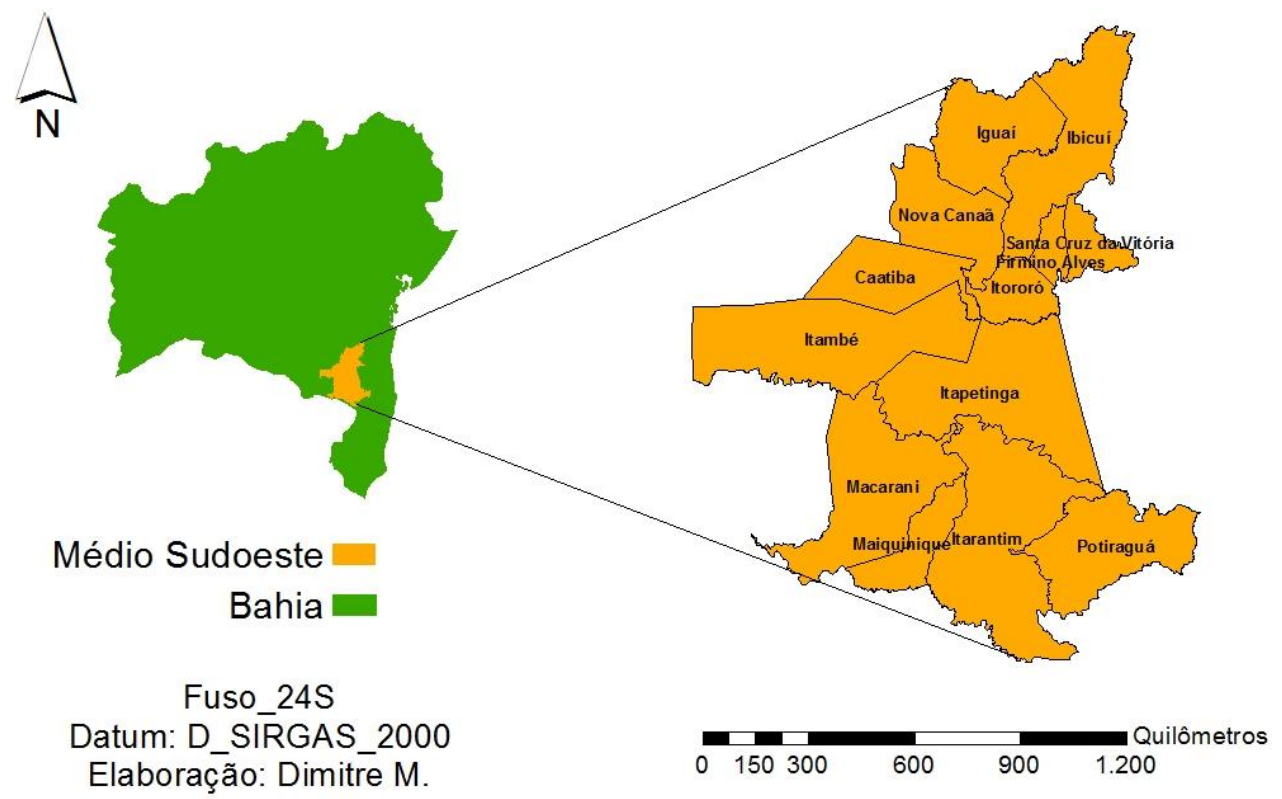

Figura 1. Localização do território de identidade onde o estudo foi desenvolvido em relação ao território do estado da Bahia

\section{A metodologia deste trabalho foi dividida em três etapas, sendo estas:}

- Coleta de solo de uma amostra composta;

- Transporte do solo para o laboratório, para uma posterior análise do material; 


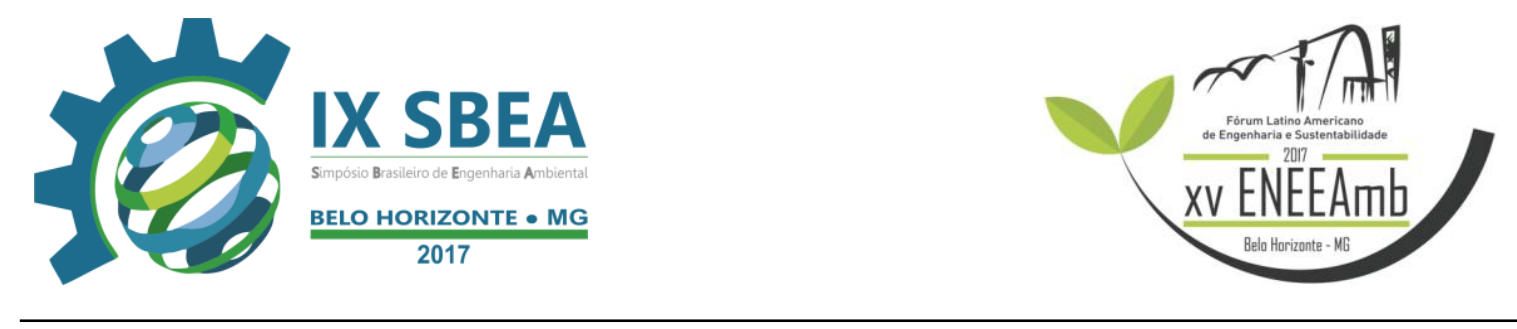

- Análise do material;

Coleta de solo de uma amostra composta(Cantarutti, 1999)

Foi selecionada uma área de 30 x 30m próximo ao sistema agroflorestal recentemente implantado no local, demarcados 15 pontos neste em forma de "zig-zag", coletados $20 \mathrm{~cm}$ de profundidade de cada um, aproximadamente $1 \mathrm{~kg}$ de cada ponto, misturado de maneira rústica em cima de uma galinhota com uma pá de ferro, e retirada uma amostra composta deste material.

Transporte do solo para o laboratório(Yamamoto, 1991)

A amostra depois de retirada foi embalada em duas sacolas plásticas de polietileno de alta densidade, colocada em uma caixa térmica (da marca MOR, de 34L), e levada para o laboratório da UESB de Itapetinga, campus Juvino Oliveira.

\section{Análise do material:}

Foram feitas as seguintes análises da amostra composta de solo em questão, baseadas no (Método Embrapa de Análise de Solos, 2016).

- Potencial Hidrogeniônico; Umidade; Capacidade de Campo; Matéria Orgânica

\section{RESULTADOS E DISCUSSÃO}

As análises serão discutidas individualmente onde serão apresentados os resultados por meio de gráficos.

\section{Potencial Hidrogeniônico}

O Potencial Hidrogeniônico $(\mathrm{pH})$ é um parâmetro utilizado para informar a acidez ou basicidade de uma solução. Ele foi analisado neste estudo em duas soluções, sendo uma delas constituída de água destilada (Figura 1), e a outra de cloreto de cálcio (Figura 2), ambas contendo uma camada de cerca de $20 \mathrm{~cm}$ do solo analisado. Foram utilizadas quatro amostras do solo na análise, e os resultados se mostraram satisfatórios, por apresentarem valores próximos à 7 , valor considerado como referencial neutro para o $\mathrm{pH}$. 


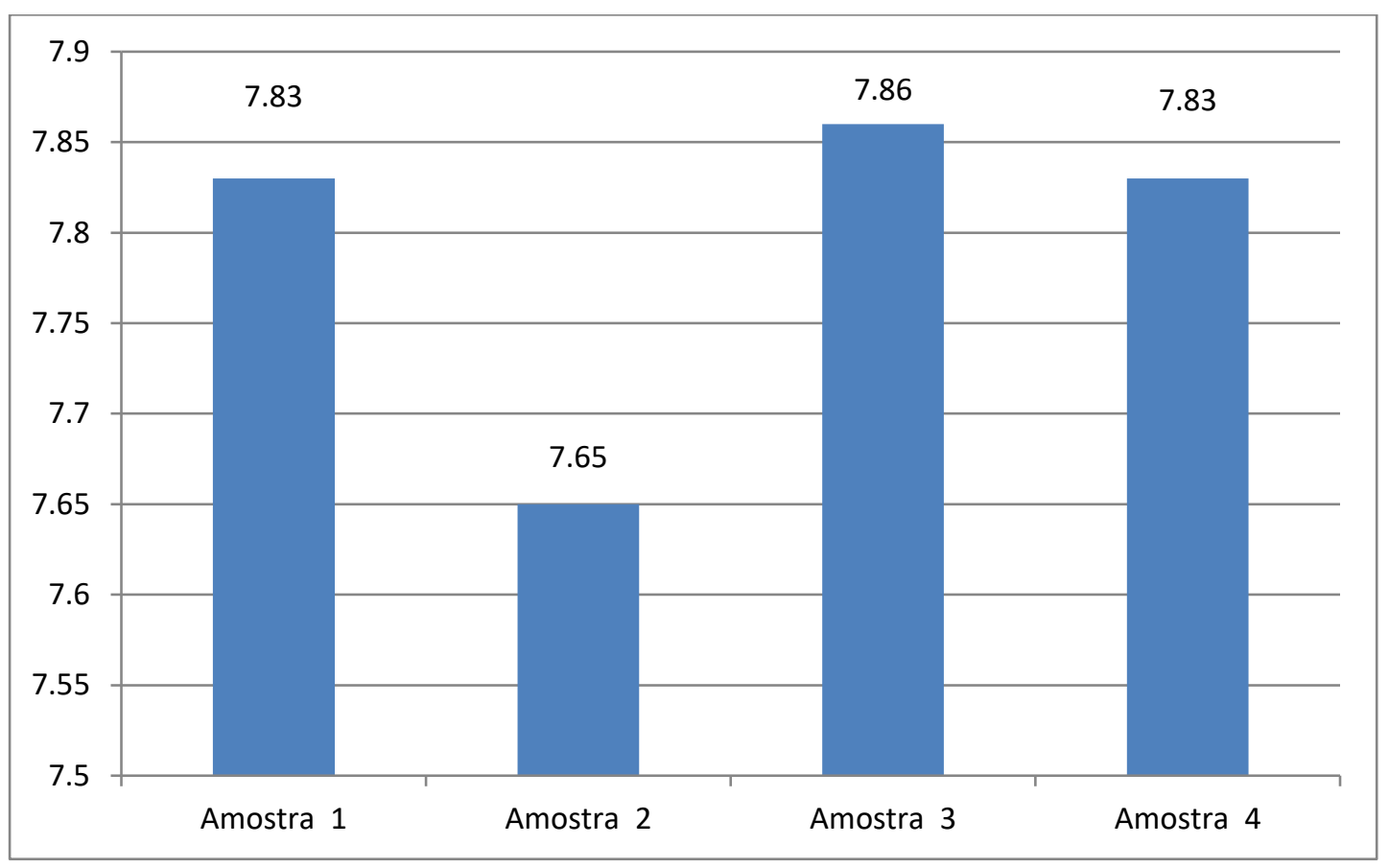

Figura 2. Valores do potencial Hidrogeniônico em água $\left(\mathrm{pH}_{\mathrm{H} 2 \mathrm{O}}\right)$.

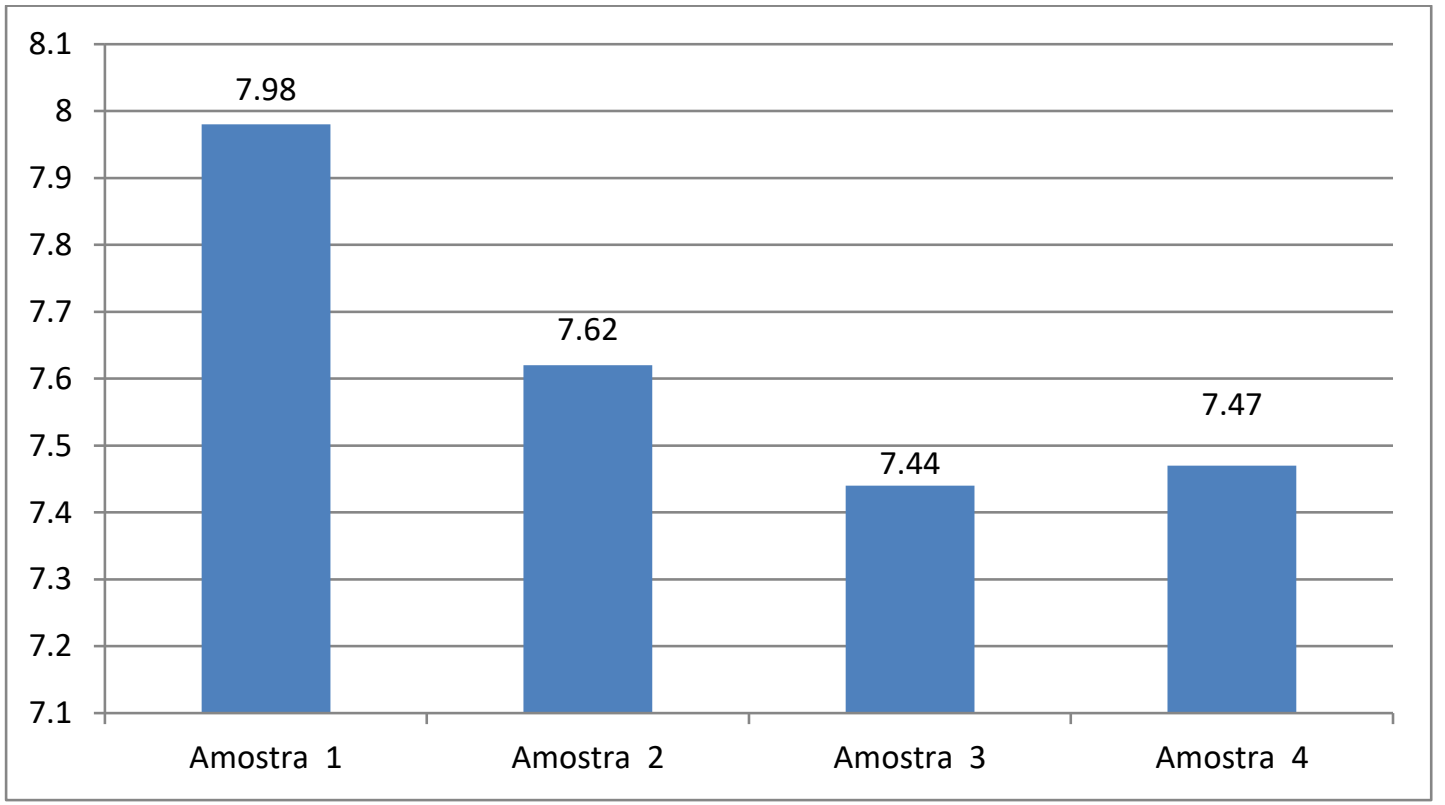

Figura 2. Valores do potencial Hidrogeniônico em cloreto de cálcio $\left(\mathrm{pH}_{\mathrm{CaCl} 2}\right)$. 


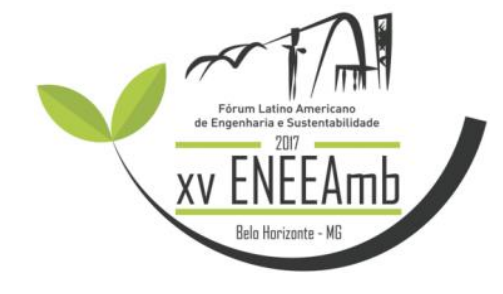

\section{Umidade}

A umidade representa a massa de água contida divido pela massa de solo seco, que pode ser expressa em termos de porcentagem ao multiplicar o resultado obtido por cem. Na Figura 4 estão apresentados os valores da umidade do solo obtidos através do método gravimétrico nas 4 amostras realizadas.

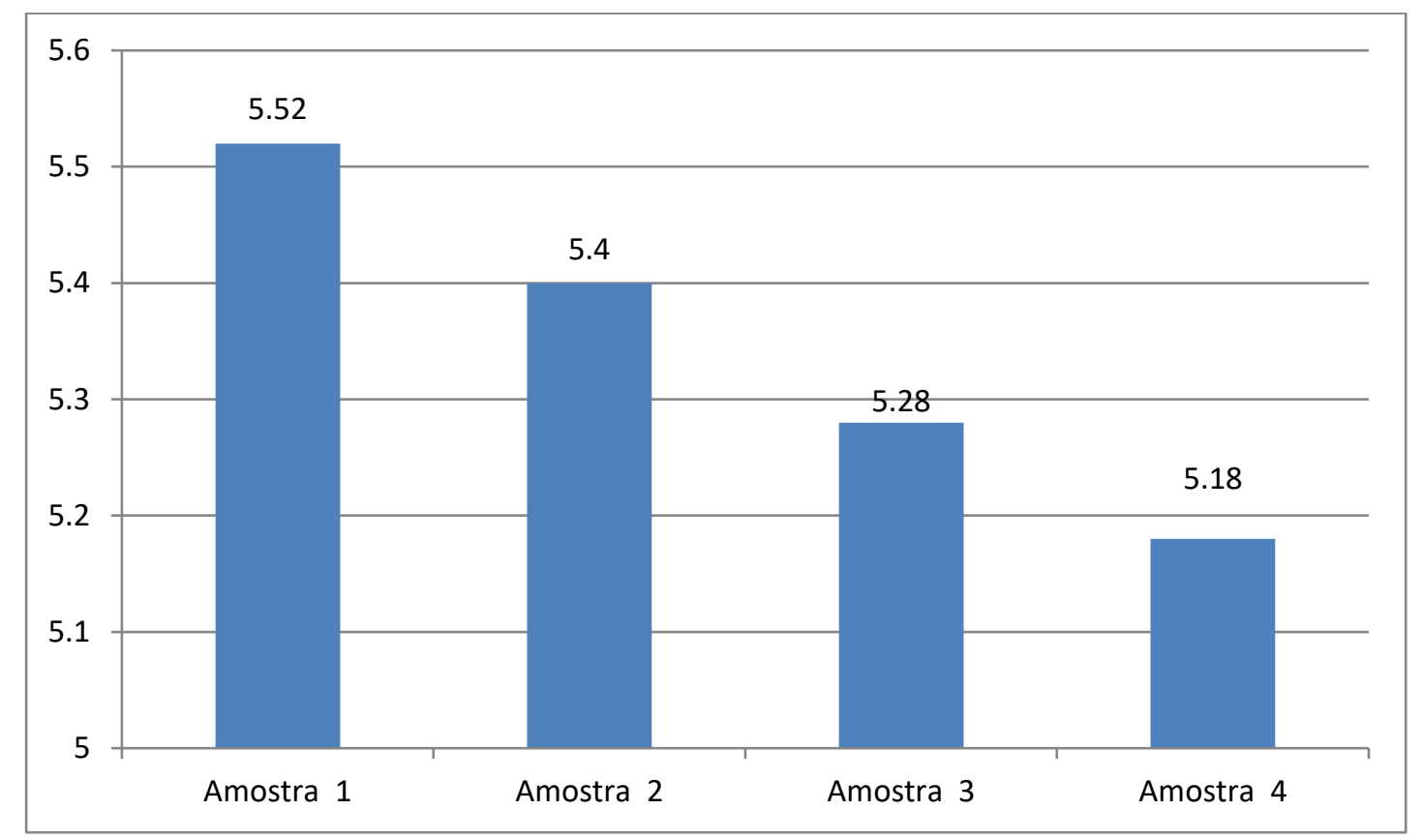

Figura 4. Valores da umidade do solo pelo método gravimétrico (\%).

\section{Capacidade de Campo}

A capacidade de campo refere-se à quantidade de água retida pelo solo quando todos os seus microporos estão carregados. As figuras a seguir demonstram gráficos de variação da água infiltrada em duas amostras do solo de acordo a variação temporal, com intervalos estabelecidos de 5, 10, 15 e 20 minutos. 

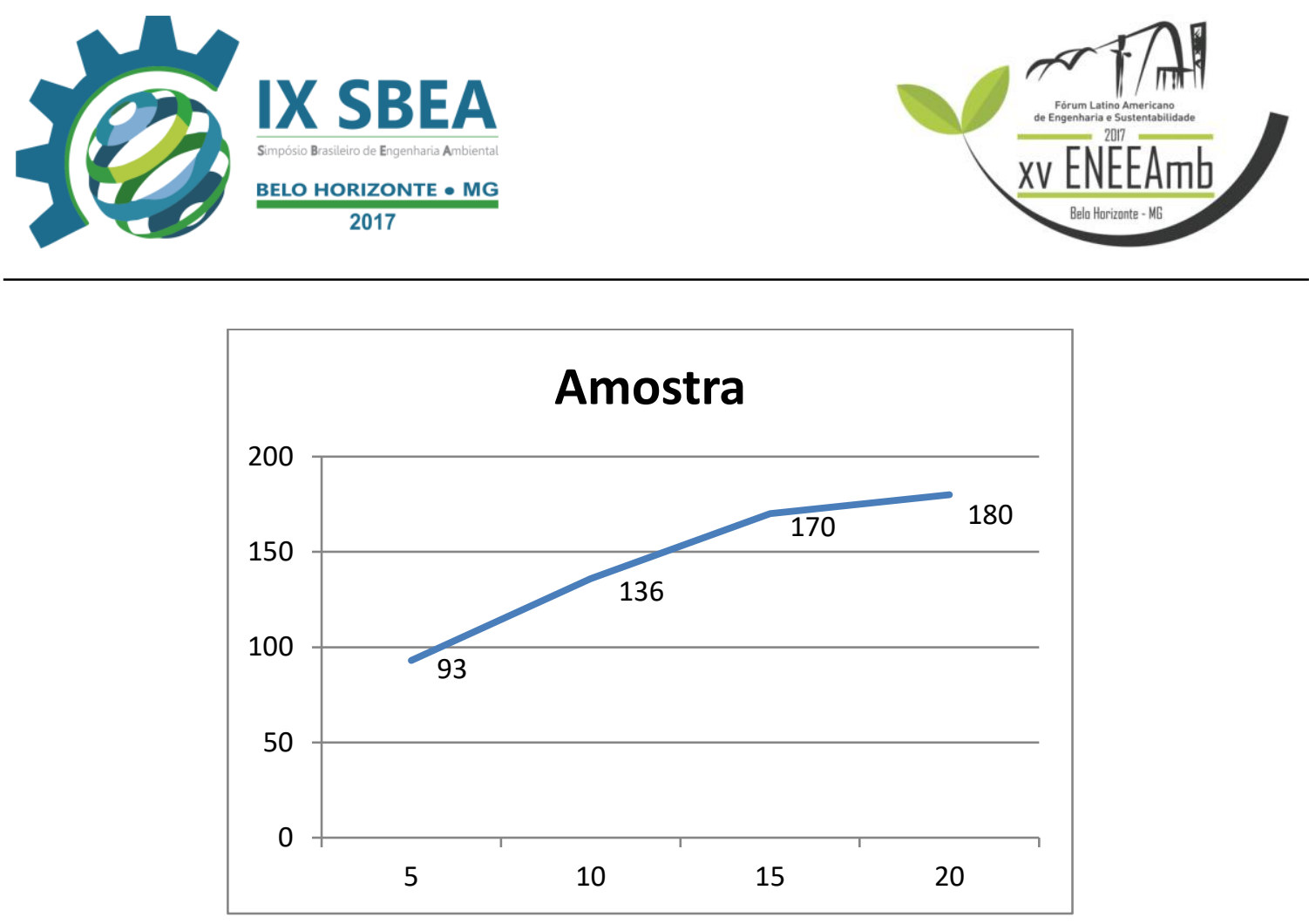

Figura 6. Infiltração da água (ml) em relação ao tempo (min). Amostra 1.

\section{Matéria Orgânica}

O teor de matéria orgânica contido num solo representa o conjunto dos compostos orgânicos presentes no ambiente. Ela está ligada com a disponibilidade de nutrientes, e com a CTC do solo. Na figura 8, poderemos observar os resultados obtidos nas 3 amostras do solo em que foram realizadas a análise.

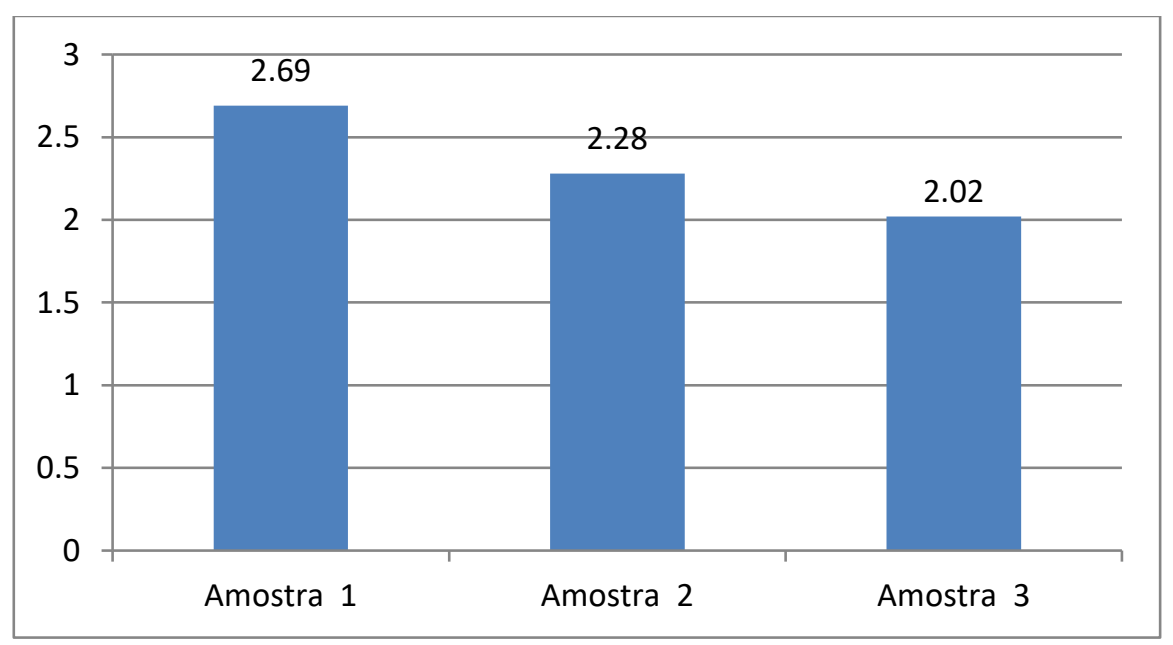

Figura 8. Quantidade de Matéria Orgânica do solo (g/kg).

\section{CONCLUSÃO}




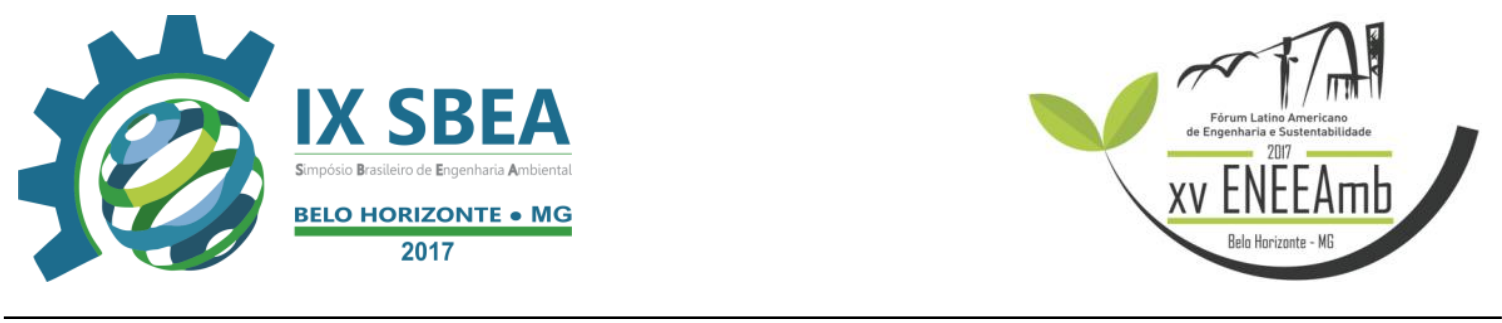

Os resultados das análises de matéria orgânica refletem as consequências do histórico de utilização de solo na região do sudoeste baiano, cujo principal atividade econômica é a pecuária extensiva. Além de compactado, as amostras de solo apresentaram baixos teores de matéria orgânica, segundo parâmetros da EMBRAPA, o que indica que o solo foi utilizado por muito tempo sem muita preocupação com a reposição da matéria orgânica.

Embora o solo tenha sido caracterizado como compactado, devido à dificuldade de coleta, os resultados das análises de capacidade de campo mostraram uma boa capacidade de infiltração durante os ensaios laboratoriais. Isso indica que a microrregião estudada é pouco susceptível à erosão hídrica, pois esta tem como princípio o escoamento superficial e para tal, é necessário que a água se acumule na superfície.

As análises de potencial hidrogeniônico foram satisfatórias, pois apresentaram valores próximos a sete (valor adotado como indicativo de neutralidade). Esta média pode ser compreendida como um bom indicativo, pois é esperado que o $\mathrm{pH}$ de solos situados dentro do domínio da vegetação Floresta Estacional Semidecidual, cujo é a vegetação original da região estudada, seja próximo a sete, sendo no máximo, solos ligeiramente ácidos, com pH em torno de seis.

Este estudo permitiu concluir que a microrregião estudada possui boas condições para a instalação de um sistema agroflorestal com plantas nativas. Os sistemas agroflorestais não possuem modelos fixos, sendo então perfeitamente adaptados a climas e regiões distintas, com diferentes características edáficas, através da utilização de diferentes consórcios de plantas. Com relação à baixa concentração de matéria orgânica, será realizada a transposição de serapilheira de remanescentes da vegetação nativa, pois esta tem como função principal, proteção e adubação gradual do solo.

Serão realizadas análises periódicas para acompanhar as mudanças nas características do solo em consequência da instalação e manejo dos módulos agroflorestais. 


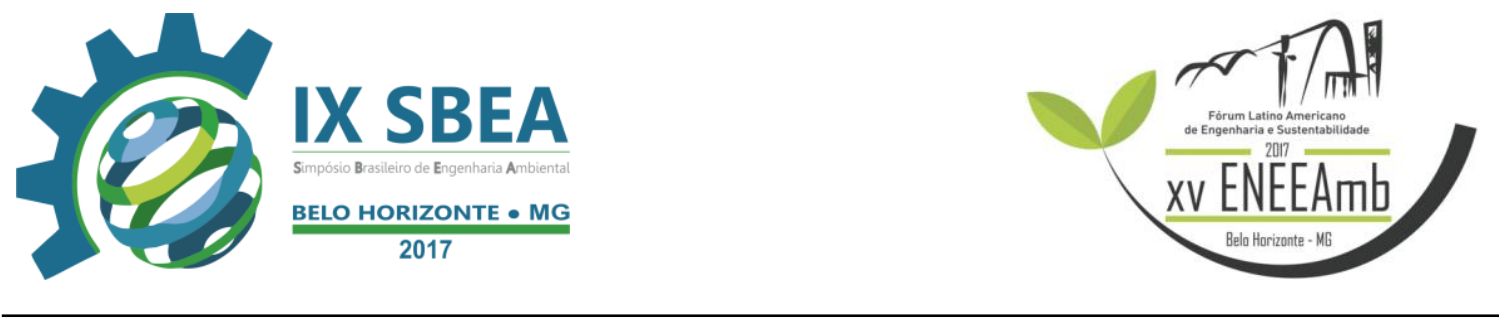

\section{REFERÊNCIAS BIBLIOGRÁFICAS}

ALBUQUERQUE, J. A; SANGOI, L; ENDER, M. Efeitos da integração lavourapecuária nas propriedades físicas do solo e características da cultura do milho. $\mathrm{R}$. Bras. Ci. Solo, 25:717-723, 2001.

ARGENTON, J. Propriedades físicas do solo em dois sistemas de cultivo com plantas de cobertura de verão intercalares à cultura do milho. Lages, Universidade do estado de Santa Catarina, 2000. 97p. (Tese de Mestrado)

BALSAN, R. Impactos decorrentes da modernização da agricultura brasileira. CAMPO-TERRITÓRIO: revista de geografia agrária, v. 1, n. 2, p. 123-151, ago. 2006.

BORGHI, E; CRUSCIOL, C. A. C; Produtividade de milho, espaçamento e modalidade de consorciação com Brachiaria brizantha em sistema plantio direto. Pesq. agropec. bras., Brasília, v.42, n.2, p.163-171, fev. 2007

CANTARUTTI, R. B.; BARROS, N. F. de; MARTINEZ, H. E. P.; NOVAIS, R. F. Avaliação da Fertilidade do Solo e Recomendação de Fertilizantes. eds. Fertilidade do Solo Viçosa, Sociedade Brasileira de Ciência do Solo, 1999. p769-872.

KLUTHCOUSKI, J.; STONE, L.F.; AIDAR, H. (Ed.). Integração lavoura-pecuária. Santo Antônio de Goiás: Embrapa Arroz e Feijão, 2003. p.25-58

MELLO, C.R.; LIMA, J.M.; SILVA, A.M. Simulação do deflúvio e vazão de pico de em micro bacia hidrográfica com escoamento efêmero. Revista Brasileira de Engenharia Agrícola. Campina Grande - PB. v.11, n.4, pág. 410-419. 2007.

MENDONÇA, E. S.; LEITE, L. F. C.; FERREIRA NETO, P. S. Cultivo de café em sistema agroflorestal: uma opção para recuperação de solos degradados. Revista Árvore, v. 25, n. 3, p. 375-383, 2001

OLIVEIRA, L.B. de.; PAULA, J.L. de. Contribuição da física de solo aos estudos sobre manejo e conservação do solo. Rio de Janeiro: EMBRAPA-SNLCS, 1983. 23p. (EMBRAPA-SNLCS. Documentos, 6).

REINERT, D. J. Recuperação de solos em sistemas agropastoris. In: DIAS, L. E.; MELLO, J. W. V (Eds.). Recuperação de áreas degradadas. Viçosa: UFV, SOBRADE, 1998. p. 163-176.

YAMAMOTO, T. Effects and consequences on bad sample experiment conducted at the place of analysis. Eds. Sun and Earth (Scientific American Library Series), p. 122-126, 1991. 